\title{
Development of Contamination-Free Restriction Fragment Length Polymorphism Probes for the Obligate Biotroph Peronospora tabacina, an Oomycete Causing Blue Mold of Tobacco
}

\author{
Serenella A. Sukno, Amy M. Taylor, and Mark Farman
}

University of Kentucky, Department of Plant Pathology, S-305 Agricultural Sciences Center, North, Lexington 40546. Current address of S. A. Sukno: 1832 Waterford Forest Circle, Cary, NC 27513.

Current address of A. M. Taylor: Department of Pharmacology and Toxicology, McGuire Hall, 112 E. Clay St., Richmond, VA 23298. Accepted for publication 25 June 2002.

ABSTRACT

\begin{abstract}
Sukno, S. A., Taylor, A. M., and Farman, M. 2002. Development of contamination-free restriction fragment length polymorphism probes for the obligate biotroph Peronospora tabacina, an oomycete causing blue mold of tobacco. Phytopathology 92:1227-1235.

Peronospora tabacina is an obligately parasitic oomycete that causes blue mold, a devastating disease of tobacco. Genetic studies of this pathogen have been hampered by the lack of molecular markers. We generated a set of molecular markers for $P$. tabacina by collecting sporangiospores from infected tobacco leaves, extracting spore DNA, and cloning it in a plasmid vector. The resulting clones were then used to probe DNA from a collection of $P$. tabacina isolates to survey for polymorphisms. Most probes gave unexpected hybridization patterns with signal intensities that varied significantly from one DNA sample to another or between different DNA preparations of the same isolate. These results indicated that certain DNA preparations contained DNA from a source other than P. tabacina, which in turn suggested that some probes might have been derived from contaminating organisms present in
\end{abstract}

the spore suspensions. Therefore, we characterized the inserts of several recombinant plasmids to determine their origins. Sequence analysis revealed that several of the inserts encoded peptides with similarity to bacterial proteins, suggesting that they were derived from bacterial contaminants. Of the remaining clones, five exhibited similarity to retroelements, one resembled eukaryotic helicase genes, and nine had no similarity to sequences in the databases. These were postulated to be true $P$. tabacina DNA clones. Verification of the origin of each probe was achieved by filtering a spore suspension, extracting DNA from the retentate and filtrate, and probing Southern blots of these DNA samples. These experiments confirmed the probe origins predicted by sequence analysis, resulting in the generation of 20 different restriction fragment length polymorphism probes that are specific for P. tabacina DNA. These probes should enable identification of reliable genetic markers for population studies of the blue mold organism.

Additional keyword: DNA fingerprinting.
Genetic markers provide useful tools for studying plant pathogen populations. For many pathogens, the availability of molecular genotyping methods has enabled investigation of genetic variation within pathogen populations $(9,23,25)$, differentiation between genetic lineages/races $(4,17)$, and insight into the genetic structure of pathogen populations $(3,21)$. Despite the rapid progress brought about by the availability of molecular markers, we still know very little about the population biology of many obligate plant parasites such as the downy mildews. This is due largely to the inherent difficulties in isolating DNA from obligate parasites, which require living host tissues for growth and which cannot be isolated in pure culture.

Many obligate plant parasites like Peronospora tabacina produce spores on the outside of the host, which can be separated from plant tissues. Extraction of DNA from these propagules enables molecular markers to be used for genetic analysis of the parasite. DNA obtained in this manner is usually available in small quantities. For this reason, the polymerase chain reaction (PCR) has been the method of choice for molecular marker analysis of obligate parasites because it provides a means of determining haplotypes with limited amounts of DNA $(6,9,18,22,24,34,39)$. However, PCR is extremely sensitive to contamination with exogenous DNA $(7,15)$. In this regard, it is important to consider that

Corresponding author: M. Farman; E-mail address: farman@uky.edu

Publication no. P-2002-0924-01R

(C) 2002 The American Phytopathological Society most plants play host to a diverse microbial community, in addition to the pathogen of interest. Consequently, it is extremely difficult to obtain nucleic acid preparations from obligate parasites in the absence of significant contamination from host DNA and DNA of other host-associated microbes.

Previous molecular studies of Peronospora spp. focused on the use of random amplified polymorphic DNA (RAPD) analysis to investigate genetic variation within the pathogen population (34, 39). Using RAPD analysis, polymorphisms were readily identified between different $P$. tabacina isolates. However, different generations of spores from a single isolate also exhibited variations in RAPD profiles (39). These results suggested that the analysis was compromised by the presence of contaminating organisms, despite the fact that the spores were subjected to filtration and washing to remove bacteria (39). However, another possibility was that $P$. tabacina has a high degree of genetic instability. Distinguishing between these alternatives requires the ability to generate contamination-free $P$. tabacina DNA, or use of molecular markers that are less sensitive to contamination.

Obtaining large numbers of contaminant-free $P$. tabacina spores is not so straightforward because samples collected from the field invariably contain large numbers of bacteria. The antibiotic neomycin sulfate has been used to control bacterial populations associated with the downy mildew Bremia lactucae (20). However, this was not successful for $P$. tabacina because neomycin, as well as ampicillin and streptomycin, were ineffective against many of the bacterial contaminants present in P. tabacina spore suspensions (S. Sukno and M. Farman, unpublished data). In 
addition, $P$. tabacina itself is sensitive to a number of antibiotics (8). One way that contamination-free $P$. tabacina spores can be obtained is to establish tissue cultures from infected tobacco leaves that have been surface-sterilized. This results in a longterm co-culture in which $P$. tabacina exists in association with the tobacco callus (10). In principle, spores from such co-cultures could be bulked-up by inoculation of axenically grown tobacco plants. However, we considered that this might be impractical to implement on the scale required by a population study.

Based on our ability to obtain large numbers of sporangiospores from $P$. tabacina-infected tobacco and, hence, to obtain sufficient quantities of $P$. tabacina DNA, we reasoned that it should be possible to minimize contamination problems by analyzing blue mold populations by restriction fragment length polymorphism (RFLP) markers. RFLP markers have been successfully applied to analysis of other obligate plant parasites such as Blumeria graminis (2) and Bremia lactucae $(12,13)$, indicating the viability of this approach. In relation to contamination issues, RFLP probes should have a distinct advantage over arbitrarily primed PCR-based markers because the inherent specificity in DNA-DNA hybridization should prevent the RFLP probes from binding to contaminating DNA. In addition, as long as the organism is propagated in a manner that does not promote excessive growth of contaminants, it should be possible to obtain clones of $P$. tabacina DNA, even from crude spore suspensions. This is because $P$. tabacina is multinucleate $(\approx 15$ nuclei per spore $)$ and its genome $\left(\geq 5 \times 10^{7} \mathrm{Mb}\right)(38)$ is approximately 10 times larger than an average bacterial chromosome $\left(4\right.$ to $5 \times 10^{6} \mathrm{Mb}$ ). Therefore, unless the contaminating organisms significantly outnumber the spores, most of the DNA extracted from spore suspensions should come from the spores themselves.

In this paper, we report on the development and characterization of contamination-free RFLP probes for P. tabacina. Despite the fact that spores were harvested from plants that generally showed little or no sign of disease before sporulation was induced, we found that the resulting spore suspensions invariably contained significant numbers of bacterial contaminants. The pervasive nature of the contamination caused problems in distinguishing genuine $P$. tabacina DNA clones from bacterial sequences. Described are two approaches that we took to verify the origin of RFLP probes. These methods are readily applicable to other obligate parasites and could be used to verify the origins of PCRbased markers such as RAPDs and amplified fragment length polymorphisms (AFLPs).

TABLE 1. Sources of Peronospora tabacina isolates used in this study

\begin{tabular}{lll}
\hline Isolate & Source & Host \\
\hline CT-96 & Connecticut & Nicotiana tabacum \\
FL-95 & Florida & N. tabacum \\
FL-97 & Alachua County, Florida & N. tabacum \\
GA-98 & Grady County, Georgia & N. tabacum \\
KY-Sc-79 & Scott County, Kentucky & N. tabacum \\
WI-98 & Rock County, Wisconsin & N. tabacum \\
PA-98 & Lancaster County, Pennsylvania & N. tabacum \\
KY-Pu-98 & Pulaski County, Kentucky & N. tabacum \\
KY-Wo-98 & Woodford, County, Kentucky & N. tabacum \\
KY-War-98 & Warren County, Kentucky & N. tabacum \\
KY-Was-98 & Washington County, Kentucky & N. tabacum \\
KY-Sh-99 & Shelby County, Kentucky & N. tabacum \\
KY-Es-98 & Estill County, Kentucky & N. tabacum \\
KY-Fa-98 & Fayette County, Kentucky & N. tabacum \\
KY-Je-98 & Jessamine County, Kentucky & N. tabacum \\
KY-Cl-98 & Clay County, Kentucky & N. tabacum \\
KY-To-98 & Todd County, Kentucky & N. tabacum \\
TN-98 & Montgomery County Tennessee & N. tabacum \\
KY-95 & Mixed population & N. tabacum \\
KY-93 & Mixed population & N. tabacum \\
VA-98 & Virginia & N. tabacum \\
TX-98-1 & Uvalde County Texas & N. repanda \\
TX-98-3 & Uvalde County, Texas & N. repanda \\
\hline
\end{tabular}

\section{MATERIALS AND METHODS}

P. tabacina isolates. All P. tabacina isolates used in this study came from commercial tobacco (Nicotiana tabacum) or wild tobacco (N. repanda) and were supplied by W. Nesmith, University of Kentucky. The place and year of collection for each isolate is listed in Table 1 . Isolates were stored frozen at $-80^{\circ} \mathrm{C}$ and recovered from storage by direct inoculation of tobacco plants (cv. KY14) after removing the dimethylsulfoxide used as a cryoprotectant (5).

Host plants. For propagation of $P$. tabacina, burley tobacco cv. KY14 was used in all experiments. KY14 was seeded in flats $(20 \times 31 \times 8 \mathrm{~cm})$ containing a peat-perlite potting mix that had been saturated with tap water. When the seedlings were approximately $2.5 \mathrm{~cm}$ in height, they were transplanted to flats $(20$ seedlings per flat) filled with a 3:1 combination of potting mix and steam-treated or methyl bromide-fumigated Maury silt loam soil from Spindletop Farm (Lexington, KY). Seedlings were preconditioned for inoculation by transferring them to a growth chamber (29). Growth chamber conditions consisted of a 12-h photoperiod under a light intensity of 125 to $150 \mu \mathrm{E} \mathrm{m}^{-2} \mathrm{~s}^{-1}$ supplied by a cool white fluorescent light and maintained at $23^{\circ} \mathrm{C}$. Plants were fertilized biweekly with a solution of Peters fertilizer (20-20-20, N-P-K; W. R. Grace \& Co., Fogelsville, PA), which was made with $15 \mathrm{ml}$ of soluble fertilizer in 3.79 liters of water.

Bacterial strains and plasmids. Escherichia coli strain DH5 $\alpha$ was used for propagating all the plasmids used in this study. No attempt was made to identify the bacteria found in association with $P$. tabacina-infected tobacco leaves. DNA extracted from $P$. tabacina spores was cloned in the vector pBlueScript $\mathrm{KS} \mathrm{\textrm {II } ^ { + }}$ (pBSKSII ${ }^{+}$, Stratagene, La Jolla, CA). Plasmid DNA was isolated from overnight shake cultures according to the boiling miniprep method (31).

Isolation of single sporangiospores. Prior to genetic analysis, each isolate was purified by two rounds of single-spore isolation. These resulting spore populations were then "bulked up" for DNA extraction by inoculation of several tobacco leaves (Fig. 1). To minimize cross-contamination, most operations (except single sporing) were performed in a containment hood (Model NU-425600; Nu-aire, Plymouth, MN) and simultaneous manipulation of different isolates was avoided. For single-spore isolation, a tobacco leaf disk containing a sporulating lesion was excised and placed in a glass beaker containing cold, sterile Nanopure water (Barnstead/Thermolyne, Dubuque, IA). The beaker was agitated by hand to suspend the spores. The spores were then counted in a hemacytometer, and the suspension was diluted to a concentration of $\approx 2$ spores per microliter. One-microliter droplets were placed on a microscope slide. Droplets containing a single spore were identified under the microscope and were used to inoculate detached leaves according to a drop inoculation method (28). Briefly, the droplets were transferred onto the surface of a young leaf (5- to 6-cm diameter) sitting on wetted filter paper in a $10-\mathrm{cm}-$ diameter plastic petri dish. The leaves were lightly sprayed with deionized water. Approximately $10 \mathrm{ml}$ of Hoagland's solution amended with kinetin $(100 \mathrm{ng} / \mathrm{ml})$ was added to each petri dish, which was then inclined at an $\approx 10^{\circ}$ angle to keep the cut end of the leaf petiole submerged in the solution. The leaves were incubated in the dark for $16 \mathrm{~h}$ at $15^{\circ} \mathrm{C}$ to allow infection to occur. They were then transferred to a growth chamber and maintained at $18^{\circ} \mathrm{C}$ under white fluorescent light (75 to $80 \mu \mathrm{E} \mathrm{m}^{-2} \mathrm{~s}^{-1}$ ) with a 12-h photoperiod. Incubation was continued until sporulation occurred (10 to 14 days). These spores were collected and used for a second round of single-spore isolation, after which they were either stored at $-80^{\circ} \mathrm{C}$ or used to infect plants for production of large quantities of spores (Fig. 1).

Propagation of $\boldsymbol{P}$. tabacina for DNA isolation. Large numbers of spores were obtained by propagating the organism in tobacco plants. Spore suspensions were either injected into leaf panels or 
sprayed onto leaf surfaces. Spraying is more likely to result in escape of spores, an occurrence that might cause blue mold outbreaks. For this reason, spray inoculation was avoided if the disease was not already active in the Kentucky tobacco crop. For infiltration, an aliquot of spores was recovered from frozen storage, filtered to remove the dimethylsulfoxide, adjusted to $\approx 10^{4}$ spores per $\mathrm{ml}$ with sterile water, and injected into panels of two expanding leaves $(\approx 10$ injection points per leaf). The plants were then transferred to a growth chamber at 18 to $23^{\circ} \mathrm{C}$ (temperature depended on chamber availability) with a 12 -h photoperiod. After 7 to 10 days of disease development, sporulation was induced by detaching the leaves, misting them with sterile Nanopure $\mathrm{H}_{2} \mathrm{O}$, and sealing them in a plastic bag. The bags were placed in the dark for 16 to $18 \mathrm{~h}$ at $18^{\circ} \mathrm{C}$. The following day, $250 \mathrm{ml}$ of cold, sterile Nanopure water was added to the bag, which was then agitated to release the spores. Suspensions were filtered through two layers of Miracloth (Calbiochem-Novatiochem Corp., La Jolla, CA) to remove leaf material and debris that was on the leaf surface.

For spray-inoculation, two 4- to 6-week-old plants were sprayed with a spore suspension $\left(\approx 10^{2}\right.$ spores per $\left.\mathrm{ml}\right)$ until run off $(\approx 100 \mathrm{ml}$ per plant). Following inoculation, the plants were covered with plastic bags and moved into the dark for 16 to $18 \mathrm{~h}$. After this, the plants were transferred to the growth chamber and treated the same as the injected plants, except that four to six leaves were used for induction of sporulation.

Storage of $\boldsymbol{P}$. tabacina cultures. $P$. tabacina cultures were stored as sporangiospore suspensions following a modification of the procedure of Dahmen et al. (5). After filtration through Miracloth, spore suspensions were vacuum-filtered through a $0.8-\mu \mathrm{m}$ nitrocellulose membrane (47-mm diameter; Millipore Corp., Bedford, MA) to reduce bacterial contamination. The spore mat was washed by passing $500 \mathrm{ml}$ of sterile Nanopure water through the filter. Spores were collected on the filter, resuspended in sterile Nanopure water, and subjected to three additional rounds of filtration. After the final resuspension, the spores were pelleted by centrifugation. Ten-microliter aliquots of the spore pellet were resuspended in $1.5 \mathrm{ml}$ of a $1 \%$ dimethyl sulfoxide (DMSO) solution, frozen at $-20^{\circ} \mathrm{C}$ for $24 \mathrm{~h}$, and transferred to $-80^{\circ} \mathrm{C}$.

Isolation and cloning of genomic DNA from P. tabacina. To ensure that contamination with other organisms was kept to a minimum, spores were harvested from leaves, which, apart from the profuse sporulation, showed little or no other signs of disease. The genomic DNA samples used for constructing plasmid libraries of $P$. tabacina DNA were isolated according to a scaled-down (microfuge tube) version of the protocol of Raeder and Broda (26). Briefly, spore pellets were resuspended in $0.5 \mathrm{ml}$ of lysis buffer $(10 \mathrm{mM}$ Tris- $\mathrm{HCl}, \mathrm{pH} 7.5,0.5 \mathrm{M} \mathrm{NaCl}$, and $10 \mathrm{mM}$ EDTA). The spores were broken open by adding $0.5 \mathrm{ml}$ of phenol/ chloroform/isoamyl alcohol and incubated at $65^{\circ} \mathrm{C}$ for $30 \mathrm{~min}$ with intermittent vortexing. Cellular debris was pelleted by centrifugation at $13,000 \mathrm{rpm}(10,000 \times g)$ for $5 \mathrm{~min}$. The supernatant was removed, and DNA was precipitated by the addition of 0.5 volume of isopropanol. The DNA pellets were washed in $70 \%$ ethanol, dried, and redissolved in $100 \mu \mathrm{l}$ of Tris-EDTA buffer. DNA concentration was determined by fluorometry.

Minilibraries were constructed from genomic DNA of three different $P$. tabacina isolates (KY-79, KY-Cl-98, and KY-Wo-98), none of which had been subjected to single-spore isolation. For each strain, $1 \mu \mathrm{g}$ of DNA was digested with PstI (New England Biolabs, Beverley, MA). Fragments range from 5 to $10 \mathrm{~kb}$ were resolved by electrophoresis, excised from the gel, and extracted with the QiaQuick kit (Qiagen, Valencia, CA). The purified fragments were ligated into PstI-digested, alkaline phosphatase-treated $\mathrm{pBSKSII}^{+}$(Stratagene, La Jolla, CA) and transformed into $E$. coli strain DH5 $\alpha$ by electroporation by a gene pulser (Bio-Rad Laboratories, Hercules, CA). Cells were plated on Luria-Bertani (LB) agar containing ampicillin $(100 \mu \mathrm{g} / \mathrm{ml}$ and X-gal). White colonies harboring recombinant plasmids were picked into $5 \mathrm{ml}$ of
LB amended with $100 \mu \mathrm{g}$ of ampicillin per $\mathrm{ml}$ and grown overnight at $37^{\circ} \mathrm{C}$ with shaking. A $0.8-\mathrm{ml}$ aliquot of each culture was amended with DMSO to a final concentration of $8 \%(\mathrm{vol} / \mathrm{vol})$ and stored at $-80^{\circ} \mathrm{C}$. Using a boiling miniprep, plasmid DNA was prepared from the remaining culture.

Southern hybridization analysis. One microgram of $P$. tabacina DNA was digested with one of two restriction endonucleases (PstI or DraI). The restricted DNA was resolved by electrophoresis in $0.5 \%$ SeaKem LE agarose gels (BioWhittaker Molecular Applications, Rockland, ME) made with $0.5 \times$ Tris-borate-EDTA. Following electrophoresis, the gels were treated with depurination, denaturation, and neutralization solutions as described by Thornbury and Farman (35) and transferred by capillary transfer onto nylon membranes (Hybond $\mathrm{N}^{+}$; Amersham Pharmacia Biotech, Piscataway, NJ). After transfer, the blots were dried for 1 to $2 \mathrm{~h}$ at $55^{\circ} \mathrm{C}$ and the DNA was cross-linked to the membrane by exposure to $1,200 \mu \mathrm{J}$ of UV light in a Spectrolinker (Spectronics Corp., Lincoln, NE).

Hybridization probes were obtained by excising plasmid inserts by Pst $\mathrm{I}$ digestion and separating them from the vector by agarose gel electrophoresis. Insert DNA was purified using the QiaQuick kit (Qiagen) and was labeled with $\left[\alpha^{32} \mathrm{P}\right] \mathrm{dCTP}$ by an oligolabeling kit (Amersham Pharmacia Biotech). Unincorporated nucleotides were removed by centrifugation through a spin column containing Sephadex G-50 (Amersham Pharmacia Biotech). The conditions used for prehybridization, hybridization, and posthybridization washes are described in detail elsewhere (35).

After hybridization and washing, the membranes were wrapped in plastic film and exposed to PhosphorImager screens (Amersham Pharmacia Biotech) for 1 to 5 days depending on the strength of the hybridization signals. Screens were scanned in a Molecular Dynamics PhosphorImager (Model 445 SI; Amersham Pharmacia Biotech) with a pixel resolution of $176 \mu \mathrm{m}$. Resulting data were quantified with ImageQuaNT 4.0 software (Amersham Pharmacia Biotech) with local average background correction. After exposure, blots were stripped in a preheated $\left(110^{\circ} \mathrm{C}\right)$ solution of $0.5 \%$ sodium dodecyl sulfate (SDS) for $20 \mathrm{~min}$ and placed in $0.1 \times \mathrm{SSC}$ ( $1 \times \mathrm{SSC}$ is $0.15 \mathrm{M} \mathrm{NaCl}$ plus $0.015 \mathrm{M}$ sodium citrate) and $0.1 \%$ SDS solution at $65^{\circ} \mathrm{C}$ overnight. Finally, they were dried and stored between paper towels.

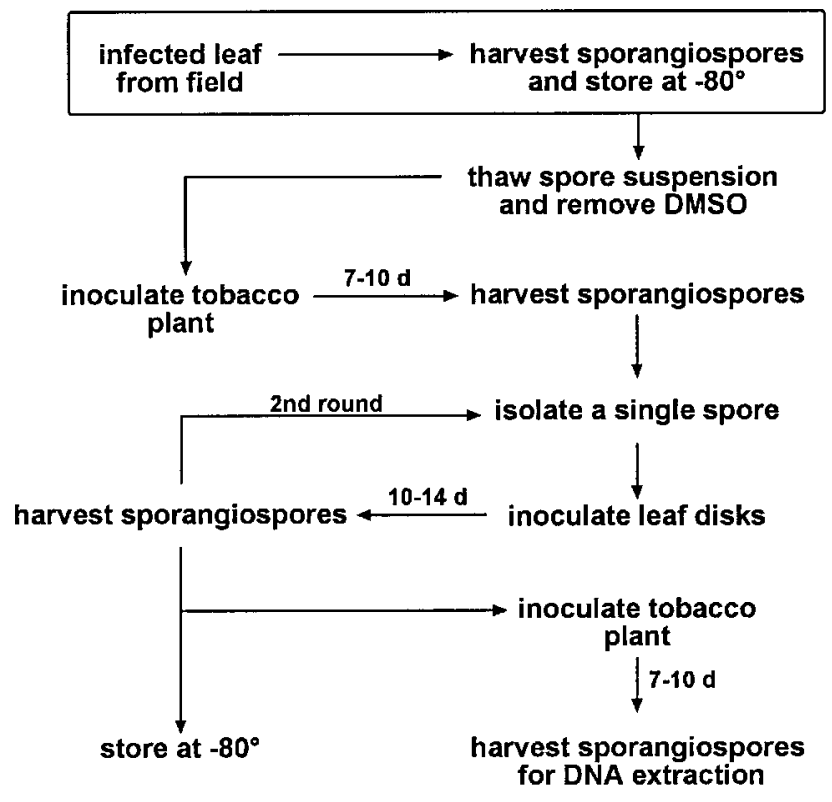

Fig. 1. Flow chart showing the steps involved in obtaining spores for DNA isolation. The steps that are boxed were performed by S. Dutton and W. Nesmith. 
Nucleotide sequence analysis. Plasmid DNA that had been isolated previously according to the boiling miniprep method (31) was further purified with the QIAprep Kit (Qiagen) according to the manufacturer's instructions. Chain termination reactions were performed using the T3 and T7 universal primers with BigDye chemistry (Perkin-Elmer, Foster City, CA). Sequence data were obtained by a sequencer (ABI Model 310; Perkin-Elmer). Sequences were compared with the nonredundant databases using the BLASTn and BLASTx algorithms (1).

Filtration of sporangiospore suspensions. The majority of contaminants in P. tabacina spore suspensions are bacteria. We used filtration not only to reduce the numbers of bacteria present in the suspensions but also to obtain samples of the bacteria present in the crude suspensions. The spore suspensions obtained from infected tobacco leaves were centrifuged at 3,000 rpm for $10 \mathrm{~min}$ in a clinical centrifuge, and the spore pellets $(\approx 2 \mathrm{ml})$ were resuspended in $10 \mathrm{ml}$ of Nanopure water. This suspension was divided into two 5-ml aliquots. One aliquot was diluted with $5 \mathrm{ml}$ of Nanopure $\mathrm{H}_{2} \mathrm{O}$ and placed on ice, and the second one was filtered through an 8- $\mu \mathrm{m}$ filter (Millipore Corp.) to separate bacterial cells from the spores. The filtrate containing bacterial cells was retained for further analysis. An additional $5 \mathrm{ml}$ of water was passed through the spore mat and this second filtrate was added to the first. The mat of spores (retentate) was then resuspended by placing the filter in $10 \mathrm{ml}$ of $\mathrm{H}_{2} \mathrm{O}$. After filtration, the three fractions were treated equally to maintain the original molar ratio of $P$. tabacina/bacterial DNA molecules present in the original (crude) spore suspension. The three suspensions were centrifuged at $5,000 \times g$ for $10 \mathrm{~min}$ to pellet all cells that were present. Nine milliliters of the supernatant was removed from each tube, and the pellets were resuspended in the remaining $1 \mathrm{ml}$ of solution. The relative concentrations of spores and bacteria in each sample were determined with a hemacytometer to count spores under the microscope. To aid in their visualization, the organisms were pretreated with the LIVE/DEAD BacLight nucleic acid stain (Molecular Probes Inc., Eugene, OR), which results in green/red fluorescence (live cells/dead cells) under UV illumination. The spores were pelleted again and resuspended in $0.5 \mathrm{ml}$ of lysis buffer, and DNA was extracted as described previously.

\section{RESULTS}

Purification of DNA for subcloning and Southern hybridization analysis. $P$. tabacina is an obligate pathogen and therefore cannot be cultured outside of its host. To obtain P. tabacina DNA that was free of host DNA, we used sporangiospores, which form on aerial hyphae (sporangiophores) emerging from the stomata of infected leaves, as starting material. For most of the $P$. tabacina isolates, it was possible to obtain large numbers of sporangiospores $\left(10^{6}\right)$ from a single, heavily infected leaf. Use of four or five leaves of a single, heavily infected tobacco plant provided sufficient DNA for most of the analyses performed in this study. Some isolates, however, did not grow well in the host, resulting in sparse sporulation. To obtain sufficient DNA for analysis of these isolates, infection and sporulation periods were allowed to proceed for longer durations. The total DNA isolated from sporangiospore suspensions of three different strains was used to create three minilibraries that contained a total of 232 plasmid clones.

Southern hybridization analysis of genomic DNA isolated from $P$. tabacina spores. To identify probes that would be useful for population studies of the blue mold organism, we prescreened the recombinant clones for their ability to identify RFLPs in DNA samples from a small, yet representative, collection of $P$. tabacina isolates. Eighty-five clones were chosen at random and used to probe Southern blots of DraI- and PstI-digested DNA from nine $P$. tabacina isolates. Each blot contained a control lane of tobacco DNA. Ethidium bromide staining and visualization of the agarose gels indicated that each of the lanes contained approximately equal quantities of DNA (data not shown).

All of the probes hybridized to genomic DNA isolated from the spore suspensions but not to the lane containing tobacco DNA (Fig. 2), indicating that the probe collection was not contaminated with host DNA. However, despite the fact that each lane was loaded with approximately equal quantities of DNA, all probes produced hybridization signals whose intensities varied significantly from one lane to the next (Fig. 2). Some probes gave no detectable hybridization at all in some lanes, indicating that these particular DNA samples had little or no homology to the probe. The most likely explanation for this was that the samples were contaminated with DNA from other leaf-associated microbes. This was especially likely because certain isolates did not sporulate well and required use of extended infection periods or more tobacco leaves to obtain sufficient spores for DNA extraction. An additional indication of contamination came from the observations that repetition of hybridization experiments with freshly extracted DNA samples result in relative signal intensities different from those obtained in experiment 1 (Fig. 2, panel C).

Some of the probes generated from genomic DNA of isolate KY-Wo-98 gave an unusually strong signal in the lane containing
A)

$\begin{array}{llllllllll}1 & 2 & 3 & 4 & 5 & 6 & 7 & 8 & 9 & \mathrm{~T}\end{array}$

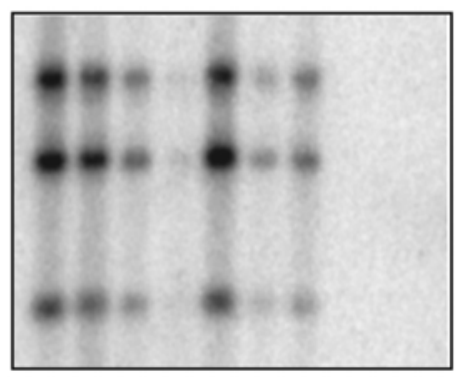

probe $=\mathrm{L} 12$
B)
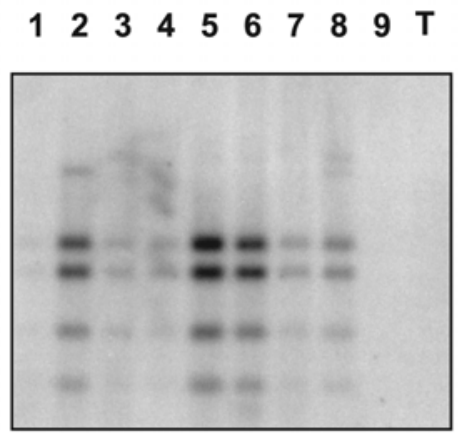

probe $=07$
C)

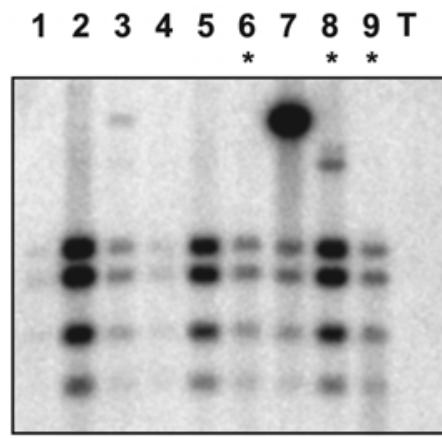

probe $=07$

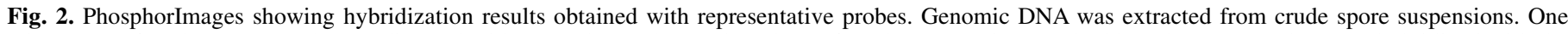

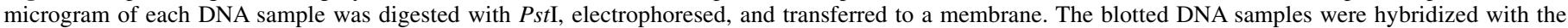

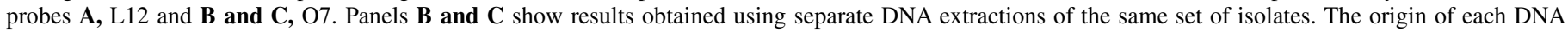

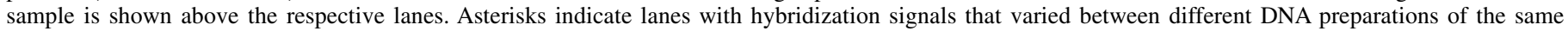
Peronospora tabacina isolates. 
DNA of KY-Wo-98 (Fig. 2, panel C, lane 7). Such results provided a strong indication that the probes themselves were derived from contaminating organisms. We had expected that a small number of the probes might be derived from microbes other than P. tabacina or the host. However, what we had not anticipated was that, in many cases, the patterns and relative intensities of hybridization did not give much of an indication as to which probes were from $P$. tabacina and which were from contaminants (Fig. 2, panels A and B). For this reason, it was necessary to characterize probes further to determine their origins.

Sequence analysis of selected probes. Inclusion of a lane of tobacco DNA in each of the Southern hybridization experiments revealed no contamination with tobacco DNA (Fig. 2). Therefore, if contamination was present, it was most likely that it came from bacteria that were on the leaf surface or colonizing the blue moldinfected tissues. To determine if any of the probes contained bacterial DNA, we sequenced the ends of the inserts from 20 plasmid clones. The rationale behind this experiment was that bacterial genomes are gene-dense. Therefore, it was expected that determination of $\approx 1 \mathrm{~kb}$ of sequence for each clone would be sufficient to identify a protein-coding region, which could be identified as bacterial in origin through database searches.
Use of BLASTx to search the nonredundant databases revealed that 8 of the 20 clones that were sequenced had significant similarity to bacterial proteins (Table 2). Four of these clones showed the highest degree of similarity to predicted protein sequences in Pseudomonas aeruginosa. Among the remaining clones, one had a low-copy insert with a sequence similar to eukaryotic $S N F 2$-like helicases (16); five clones contained sequences that were highly repetitive and showed similarity to retroelements found in vertebrates, fungi, plants, and insects; and six clones showed no matches to sequences in the databases (Table 2).

Verification of clone origin by Southern hybridization analysis of DNA extracted from filtered spore suspensions. To confirm the tentative conclusions drawn from the sequence analysis, we divided a spore suspension into two parts and filtered one half to separate out the bacterial contaminants. Three fractions were thus obtained: fraction 1 consisted of the original spore suspension containing bacteria; fraction 2 contained purified spores; and fraction 3 contained the bacteria that were removed in the process of generating fraction 2 (Fig. 3). The effectiveness of the filtration procedure was determined with a hemacytometer to establish the relative concentrations of spores and bacteria following treatment with the LIVE/DEAD BacLight nucleic acid stain.

TABLE 2. Results of BLASTx analysis of selected DNA clones used as probes

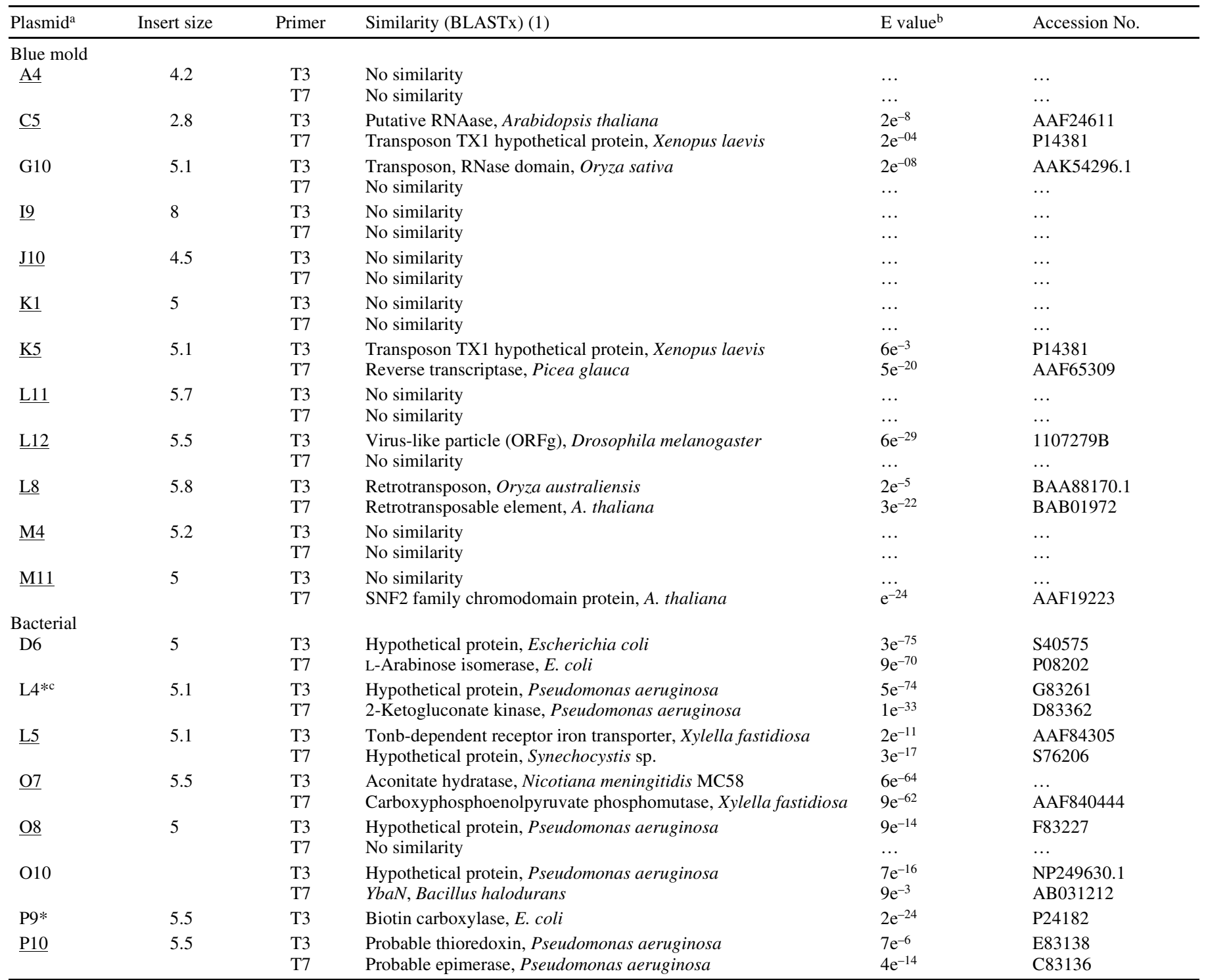

${ }^{a}$ Underlined type indicates markers whose origins were confirmed by filtration and hybridization.

b The expect (E) value is a parameter that describes the number of hits one can "expect" to see just by chance when searching a database of a particular size.

${ }^{c}$ Asterisks indicate markers for which no hybridization was detected in the filtration and hybridization experiments. 
Table 3 shows the results of two experiments. Filtration followed by a single wash step resulted in $\approx 14$ - and $\approx 2.5$-fold reductions in bacterial contamination in experiments 1 and 2 , respectively. The difference in the degree of purification achieved in the two experiments appears to be due to an inability to reduce the contamination below a ratio of approximately $2: 1$ bacteria/spore (A. Taylor and M. Farman, unpublished data). This is probably because bacteria remain trapped in the mat of filtered spores. Despite the inability to remove bacteria from the spores completely, the filtration was successful in excluding spores from fraction 3 (Table 3 ).

DNA was extracted from the three fractions, digested with PstI, electrophoresed, and Southern blotted to a membrane. The blotted DNA was then hybridized sequentially with selected probes. The
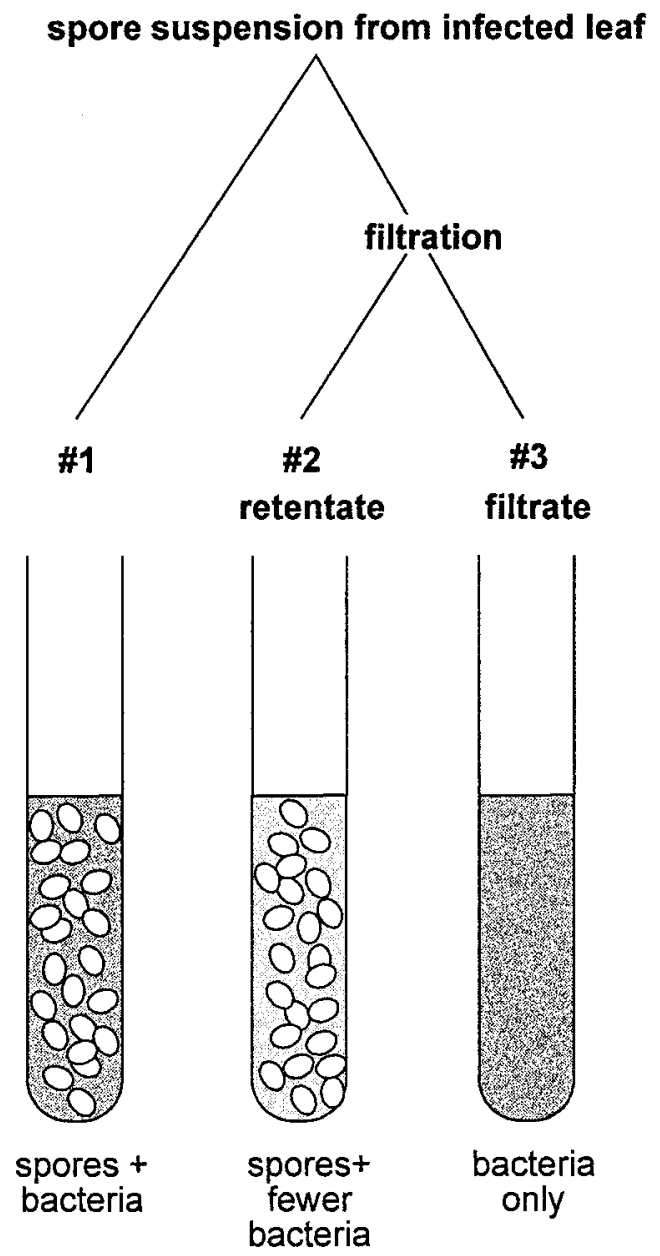

Fig. 3. Separation of Peronospora tabacina spores from bacterial contaminants by filtration. Ten milliliters of a sporangiospore suspension was divided into two 5-ml aliquots. One aliquot was saved (fraction 1) and the other was filtered with an 8 - $\mu \mathrm{m}$ membrane. The spore mat was washed by passing an additional $5 \mathrm{ml}$ of Nanopure $\mathrm{H}_{2} \mathrm{O}$ through the filter. The spores were then resuspended in $10 \mathrm{ml}$ of Nanopure $\mathrm{H}_{2} \mathrm{O}$ to give fraction 2. The filtrate was saved to give fraction 3 . The cells in each fraction were pelleted by centrifugation and DNA was extracted. origin of each probe DNA was easily determined based on its hybridization pattern. As shown in Figure 4, probes D6 and P10 hybridized to all three lanes of DNA. Lane 3 contains DNA that is exclusively bacterial in origin, confirming that probes D6 and P10 were derived from bacterial contaminants. These probes also hybridized to the DNA sample from fraction 2 (Fig. 4), due to the inability of the filtration procedure to remove bacteria completely. In contrast, probes $\mathrm{K} 1, \mathrm{~K} 5$, and M11 hybridized only to the DNA samples in fractions 1 and 2 and are therefore clearly clones of $P$. tabacina DNA. The lack of hybridization between the repetitive probes $\mathrm{K} 1$ and $\mathrm{K} 5$ and the DNA from fraction 3 demonstrates that there is little or no passage of free $P$. tabacina DNA through the filter. Consequently, if a probe hybridizes to DNA from this fraction, this provides convincing evidence that it is from a contaminating microbe. Probes L4 and P9 did not hybridize to any of the DNA samples (data not shown), indicating that they likely came from a bacterium (or bacteria) that was (were) not present in the spore suspensions used for these experiments.

Analysis of DNA from filtered spore preparations provided a reliable means to verify the origin of our RFLP probes. Of the 20 clones that were sequenced, 16 were also used to probe panels of DNA from the three fractions. There was a perfect correspondence between a clone's origin as predicted by sequence analysis versus its actual origin as determined by experimentation (Table 2 ).

Use of verified probes for RFLP analysis of $\boldsymbol{P}$. tabacina. Our original rationale for developing RFLP markers was that once probes for a target organism had been developed, they should be relatively insensitive to the presence of DNA from contaminating organisms. To test this prediction, we used confirmed $P$. tabacina markers to survey for RFLPs in DNA samples from unpurified spore suspensions of $20 \mathrm{P}$. tabacina isolates. Many of these samples contained significant amounts of bacterial DNA, as revealed by Southern hybridization analysis with the bacterial probe D6 (Fig. 5A). Particularly heavy contamination is evident in the KY-95 and KY-Fa-98 samples, which resulted from allowing infections to proceed longer than usual to counter low levels of sporulation. Interestingly, the hybridization patterns produced by the D6 probe were highly polymorphic, indicating that most spore suspensions contained several different bacterial genotypes. Moreover, these genotypes varied from sample to sample. Despite these high levels of bacterial contamination, it was still possible to determine marker haplotypes for genuine $P$. tabacina probes. Figure $5 \mathrm{~B}$ shows the results obtained with probe M11. The monomorphic pattern produced by this marker gives a clear indication that it hybridizes specifically to the P. tabacina DNA. Several other confirmed blue mold probes showed a similar high level of specificity for the P. tabacina DNA (data not shown). Thus, the RFLP markers developed in this study effectively surmount the problem of bacterial contamination in P. tabacina spore suspensions.

\section{DISCUSSION}

Studies of obligate parasites are complicated by the requirement of living host tissues for their propagation. Molecular studies can be particularly challenging due to the difficulty in obtaining sufficient quantities of DNA that are not overly contaminated with DNA from other organisms. Previous molecular studies of $P$. taba-

TABLE 3. Spore and bacterial counts before and after filtration

\begin{tabular}{|c|c|c|c|c|c|c|}
\hline & \multicolumn{2}{|c|}{ Prefiltration } & \multicolumn{4}{|c|}{ Postfiltration } \\
\hline & \multicolumn{2}{|c|}{ Fraction 1} & \multicolumn{2}{|c|}{ Fraction 2} & \multicolumn{2}{|c|}{ Fraction 3} \\
\hline & Spores $\left(\times 10^{-5} / \mathrm{ml}\right)$ & Bacteria $\left(\times 10^{-5} / \mathrm{ml}\right)$ & Spores $\left(\times 10^{-5} / \mathrm{ml}\right)$ & Bacteria $\left(\times 10^{-5} / \mathrm{ml}\right)$ & Spores $\left(\times 10^{-5} / \mathrm{ml}\right)$ & Bacteria $\left(\times 10^{-5} / \mathrm{ml}\right)$ \\
\hline Experiment 1 & 2 & 76.2 & 6.5 & 17.8 & 0 & 44.5 \\
\hline Ratio & 1 & 38 & 1 & 2.7 & 0 & 1 \\
\hline Experiment 2 & 3 & 31 & 4.5 & 23 & 0 & 10 \\
\hline Ratio & 1 & 10.3 & 1 & 4 & 0 & 1 \\
\hline
\end{tabular}


cina suggested that even filtered spore suspensions still contained contaminating microbes that interfered with RAPD experiments (39). Therefore, we sought to develop a collection of RFLP markers for P. tabacina, because these should be less sensitive to the presence of such contamination. This, in turn, should obviate the need to include elaborate procedures for reducing or eliminating contamination during the propagation of large numbers of isolates required for population studies.

While screening probes for their ability to identify polymorphisms, it soon became apparent that some of them might be derived from other microbes present in the spore suspensions. This was not entirely unexpected, although we did not anticipate that the bacterial populations would be quite so large because the leaves generally looked healthy before sporulation was induced. Almost all spore suspensions had bacterial contamination at levels that were detectable by Southern hybridization (Fig. 5A), and quantification of contamination in a suspension of spores from KY-Wo-98 revealed that bacteria were $\approx 40$ times more abundant than spores. Furthermore, Southern hybridization with bacterial probes revealed significant levels of contamination persisted even after filtration (Fig. 4, panels A to C). Thus, we were able to confirm Wiglesworth's previous suspicions (39). It is likely that similar contaminants are associated with most obligate parasites. Therefore, extreme care should be taken when interpreting molecular data for these organisms. This is particularly true when using arbitrarily primed PCR methods, because unlike RFLP analysis, random amplification gives no indication whether amplified fragments are truly from the organism under study and the contaminant population can be extremely diverse (Fig. 5A).

PCR-based markers derived by random priming have been used in a number of molecular studies of downy mildews $(27,34,37)$. However, the DNA samples used in these studies were apparently not purified of contaminants. Our results with P. tabacina would tend to suggest that some of the fragments analyzed in these studies were not actually from the organisms of interest. For example, a cDNA-AFLP analysis of $P$. parasitica genes expressed in planta, resulted in identification of 16 transcripts, 2 of which encoded peptides with similarity to bacterial proteins (37). Based on

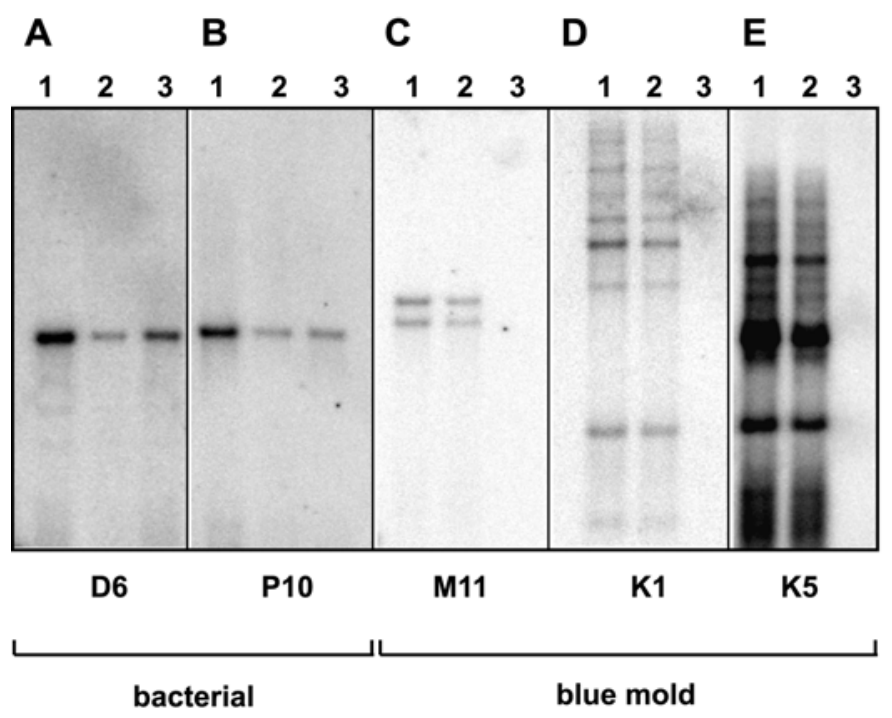

Fig. 4. Verification of clone origin by Southern hybridization analysis of filtered spores. Sporangiospore suspensions were filtered to produce three fractions (Fig. 3). DNA was extracted from each fraction, digested with Pst I, electrophoresed, and blotted to membranes. Panels A to E show PhosphorImages obtained after hybridization with the probes indicated beneath each panel. Within each panel, lane 1 contains DNA isolated from crude spores (fraction 1); lane 2 contains DNA from a filtered spore suspension (fraction 2); and lane 3 contains bacterial DNA isolated from the filtrate (fraction 3 ). our results (Table 2), it seems likely that these transcripts were actually from contaminating bacteria. A commonly used method for confirming the origin of random-primed PCR-based markers is to sequence them so that specific primers may be used to reamplify them from DNA extracted from spores $(34,37)$. While such experiments can usually exclude the host as a source of contamination, our results demonstrate that such experiments are insufficient to rule out the possibility that markers come from microbial contaminants.

For randomly primed PCR-based analyses, the number of false markers produced by contaminants is dependent on the number of different contaminants present in a spore suspension and the relative genome sizes of the contaminants and the organism under study. The abundance of contaminating DNA in relation to the DNA of the target organism is not so critical. In fact, even visually undetectable levels of contamination can lead to false marker fragments in RAPD and AFLP experiments (7). In light of these results, it is clear that band intensities are unreliable indicators of marker validity. It could be argued that an occasional false marker should not have a material affect on the outcome of most studies. However, our results indicate that false markers tended to be far more polymorphic than genuine $P$. tabacina probes (Fig. 5) (32). This clearly illustrates the importance of verifying the origins of all genetic markers for obligate parasites.

In the present study, our lack of knowledge about the specific composition of each genomic DNA sample meant that each probe's origin was not obvious from its hybridization pattern. This
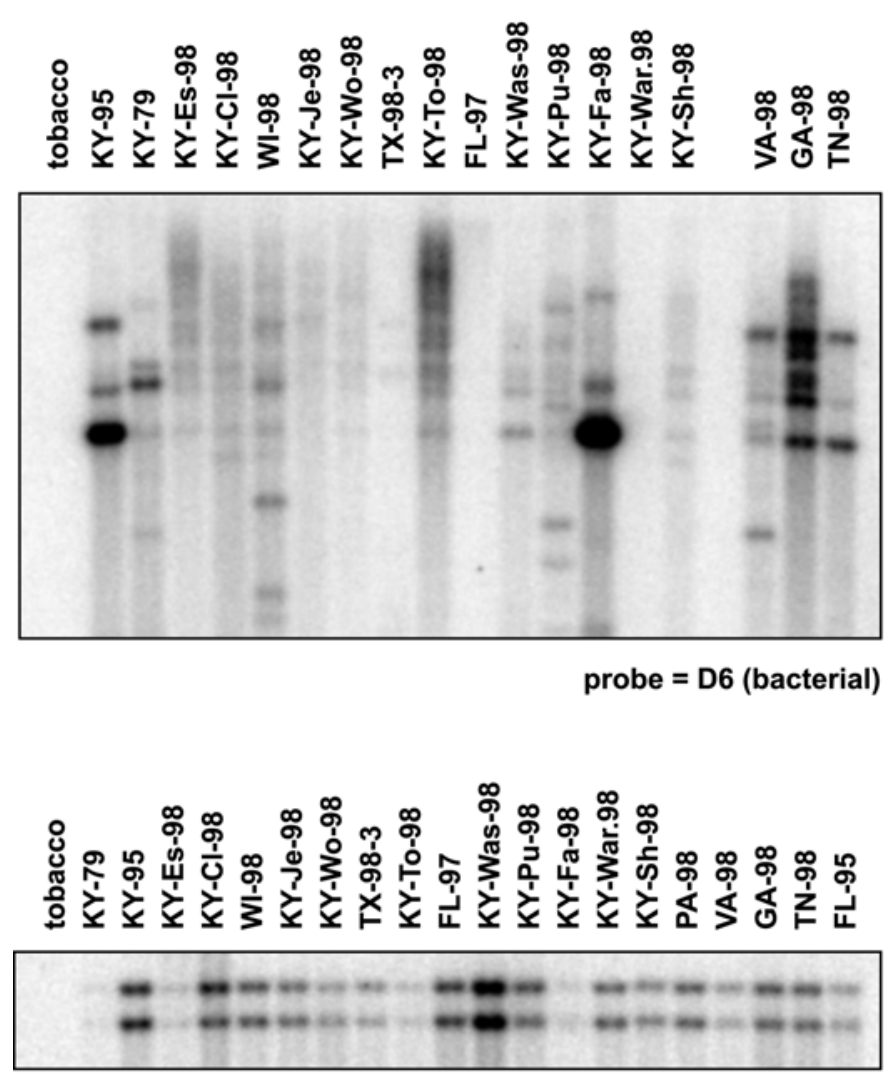

probe $=$ M11 $($ blue mold $)$

Fig. 5. Use of a confirmed Peronospora tabacina probe for restriction fragment length polymorphism analysis of several field isolates. DNA was extracted from unpurified spore suspensions and digested with PstI. After electrophoresis, the samples were transferred to a membrane and probed with the bacterial probe D6. The resulting PhosphorImage is shown in top figure. A second membrane containing a near identical set of DNA samples was probed with the confirmed $P$. tabacina probe M11. The resulting PhosphorImage is shown in bottom figure. 
is well illustrated in Figure 2 (panels A and B), which shows that probes for P. tabacina (panel A) and bacteria (panel B) were indistinguishable because they gave similar signal strengths and laneto-lane variation. The problem of probe validation was compounded by the fact that different spore suspensions contained different contaminants (Fig. 5A), which meant that DNA extracted from leaf washings of mock-inoculated tobacco was not useful as a control for identifying contaminating probes. In retrospect, it seems likely that these problems would have been minimized had the probes been made from DNA extracted from filtered spores or if the P. tabacina DNA had been separated from contaminating DNA prior to cloning (11). Nonetheless, the methods we used to characterize the clones generated in this study were simple to perform and the resulting data leave no doubt as to which clones were derived from $P$. tabacina. Consequently, it would be wise to employ such methods routinely for validating genetic markers for obligate parasites.

Sequence analysis revealed that some probes had significant nucleotide sequence similarity to bacterial genomes (data not shown). These clones were clearly derived from bacterial contaminants. For several other probes, BLASTx analysis implied that they also came from bacteria (Table 2). Although it is possible for eukaryotic proteins to share amino acid similarity with bacterial orthologs, use of filtration and hybridization to confirm the origin of each clone revealed that all of the suspect probes were indeed derived from bacteria. Significantly, the majority of contaminating probes showed similarity to genes from Pseudomonas aeruginosa (Table 2), indicating that the major contaminants of $P$. tabacina spore preparations are likely pseudomonads.

Among the remaining clones, several showed peptide sequence similarity to retroelements. These clones also produced multicopy hybridization signals when used to probe genomic DNA. We were reasonably confident that these sequences were from $P$. tabacina because retroelements have been found in the oomycetes (36) but are rare in bacteria $(14,32)$. In addition, repetitive elements in bacteria do not attain copy numbers as high as those that we observed $(19,30)$. We also anticipated that low-copy sequences showing no similarity to sequences in the databases would be from $P$. tabacina, because noncoding DNA is generally far more abundant in eukaryotes than in prokaryotic chromosomes. In addition, the databases contain less complete information on eukaryotic genomes. Again, these speculations were confirmed by filtration and hybridization. Therefore, in addition to revealing the true origin of each RFLP probe, these experiments validated sequence analysis as a simple and reliable way to identify contaminating probes. The methods that we used to validate RFLP probes could be readily adapted to confirm the origins of PCR-based markers. Sequencing is easily applied to RAPD fragments but it may not be as straightforward for AFLPs. In this case, filtration of spore suspension followed by AFLP analysis of the retentate and filtrate DNA could be used to determine the origins of each band in an AFLP profile. True marker fragments should be readily identified as those that are not amplified from the filtrate DNA.

To date, we have verified the origin of 28 clones by sequencing and/or filtration and hybridization analysis, resulting in the generation of 20 distinct RFLP probes for P. tabacina (only 12 of which are listed in Table 2). As expected, when these probes were used for hybridization analysis of DNA extracted from spores, they were not adversely affected by the levels of contamination typically found in unpurified suspensions (Fig. 5B). Therefore, a modest amount of probe characterization resulted in the production of a set of robust markers for the blue mold organism. These probes obviate the need for methods to decontaminate spore preparations used for DNA extraction as long as the spores are harvested from plants that look reasonably healthy at the time of sporulation. In an accompanying paper, we describe the use of these probes for analysis of $P$. tabacina isolates from Kentucky and other regions of the United States (33).

\section{ACKNOWLEDGMENTS}

This research was supported by a grant from the Tobacco \& Health Research Institute (THRI). This manuscript is Kentucky Agricultural Experiment Station publication 02-12-121. We thank W. Nesmith for his assistance and guidance in all aspects of this project; S. Dutton for teaching us how to culture P. tabacina; D. Thornbury and D. Brown for technical assistance; and W. Nesmith and S. A. Ghabrial for review of this manuscript.

\section{LITERATURE CITED}

1. Altschul, S. F., Gish, W., Miller, W., Myers, E. W., and Lipman, D. J. 1990. Basic local alignment search tool. J. Mol. Biol. 215:403-410.

2. Brown, J. K. M. 1990. The use of DNA polymorphisms to test hypotheses about a population of Erysiphe graminis f. sp. hordei. Plant Pathol. 39:391-401.

3. Chen, R. S., and McDonald, B. A. 1996. Sexual reproduction plays a major role in the genetic structure of populations of the fungus, Mycosphaerella graminicola. Genetics 142:1119-1127.

4. Crowhurst, R. N., Hawthorne, B. T., Rikkerink, E. H., and Templeton, M. D. 1991. Differentiation of Fusarium solani f. sp. curcurbitae races 1 and 2 by random amplification of polymorphic DNA. Curr. Genet. 20: 391-396.

5. Dahmen, H., Staub, T., and Schwinn, F. J. 1983. Technique for long-term preservation of phytopathogenic fungi in liquid nitrogen. Phytopathology 73:241-246.

6. Délye, C., Corio-Costet, M.-F., and Laigret, F. 1995. A RAPD assay for strain typing of the biotrophic grape powdery mildew fungus Uncinula necator using DNA extracted from the mycelium. Exp. Mycol. 19:234237.

7. Dyer, A. T., and Leonard, K. J. 2000. Contamination, error, and nonspecific molecular tools. Phytopathology 90:565-567.

8. Grosso, J. J. 1954. Control of tobacco blue mold by antibiotics. Plant Dis. Rep. 38:333.

9. Hamelin, R. C., Doudrick, R. L., and Nance, W. L. 1994. Genetic diversity in Cronartium quercuum f. sp. fusiforme on loblolly pines in southern U.S. Curr. Genet. 26:359-363.

10. Heist, E. P., Nesmith, W. C., and Schardl, C. L. 2001. Cocultures of Peronospora tabacina and Nicotiana species to study host-pathogen interactions. Phytopathology 91:1224-1230.

11. Hosny, M., van Tuinen, D., Jacquin, F., Füller, P., Zhao, B., GianinazziPearson, V., and Franken, P. 1999. Arbuscular mycorrhizal fungi and bacteria: How to construct prokaryotic DNA-free genomic libraries from the Glomales. FEMS Microbiol. Lett. 170:425-430.

12. Hulbert, S. H., Ilott, T. W., Legg, E. J., Lincoln, S. E., Lander, E. S., and Michelmore, R. W. 1988. Genetic analysis of the fungus, Bremia lactucae, using restriction fragment length polymorphisms. Genetics 120:947-958.

13. Hulbert, S. H., and Michelmore, R. W. 1988. DNA restriction fragment length polymorphism and somatic variation in the lettuce downy mildew, Bremia lactucae. Mol. Plant-Microbe Interact. 1:17-24.

14. Inouye, S., Sunshine, M. G., Six, E. W., and Inouye, M. 1991. Retronphage phi R73: An E. coli phage that contains a retroelement and integrates into a tRNA gene. Science 252:969-971.

15. Kwok, S., and Higuchi, R. 1989. Avoiding false positives with PCR. Nature 339:237-238.

16. Laurent, B. C., Yang, X., and Carlson, M. 1992. An essential Saccharomyces cerevisiae gene homologous to $S N F 2$ encodes a helicase-related protein in a new family. Mol. Cell. Biol. 12:1893-1902.

17. Levy, M., Romao, J., Marchetti, M. A., and Hamer, J. E. 1991. DNA fingerprinting with a dispersed repeated sequence resolves pathotype diversity in the rice blast fungus. Plant Cell 3:95-102.

18. Lui, J. Q., and Kolmer, J. A. 1998. Molecular and virulence diversity and linkage disequilibria in asexual populations of the leaf rust fungus, Puccinia recondita. Genome 41:832-840.

19. Mahillon, J., Leonard, C., and Chandler, M. 1999. IS elements as constituents of bacterial genomes. Res. Microbiol. 150:675-687.

20. Michelmore, R. W., and Crute, I. R. 1983. A method for determining the virulence phenotype of isolates of Bremia lactucae. Trans. Brit. Mycol. Soc. 79:542-546.

21. Milgroom, M. G., Lipari, S. E., and Powell, W. A. 1992. DNA fingerprinting and analysis of population structure in the chestnut blight fungus, Cryphonectria parasitica. Genetics 131:297-306.

22. Newton, A. C., Hackett, C. A., and Guy, D. A. 1998. Diversity and complexity of Erysiphe graminis f. sp. hordei collected from barley cultivar mixtures or barley plots treated with an elicitor. Eur. J. Plant Pathol. 104:925-931.

23. O'Neill, N. R., van Berkum, P., Lin, J.-J., Kuo, J., Ude, G. N., Kenworthy, W., and Saunders, J. A. 1997. Application of amplified re- 
striction fragment length polymorphism for genetic characterization of Colletotrichum pathogens of alfalfa. Phytopathology 87:745-750.

24. Pei, M. H., Whelan, M. J., Halford, N. G., and Royle, D. J. 1997. Distinction between stem- and leaf-infecting forms of Melampsora rust on Salix viminalis using RAPD markers. Mycol. Res. 101:7-10.

25. Pongam, P., Osborn, T. C., and Williams, P. H. 1999. Assessment of genetic variation among Leptosphaeria maculans isolates using pathogenicity data and AFLP analysis. Plant Dis. 83:149-154.

26. Raeder, U., and Broda, P. 1985. Rapid preparation of DNA from filamentous fungi. Lett. Appl. Microbiol. 1:17-20.

27. Rehmany, A. P., Lynn, J. R., Tor, M., Holub, E. B., and Beynon, J. L. 2000. A comparison of Peronospora parasitica (Downy Mildew) isolates from $A$. thaliana and $B$. oleracea using amplified fragment length polymorphisms and internal transcribed spacer 1 sequence analyses. Fungal Genet. Biol. 30:95-103.

28. Reuveni, M., Nesmith, W. C., and Siegel, M. R. 1985. Bioassays using detached tobacco leaves to determine the sensitivity of Peronospora tabacina to fungicides. Pestic. Sci. 16:244-250.

29. Reuveni, M., Nesmith, W. C., and Siegel, M. R. 1986. Symptom development and disease severity in Nicotiana tabacum and $N$. repanda caused by Peronospora tabacina. Plant Dis. 70:727-729.

30. Romero, D., Martinez-Salazar, J., Ortiz, E., Rodriguez, C., and ValenciaMorales, E. 1999. Repeated sequences in bacterial chromosomes and plastids: A glimpse from sequenced genomes. Res. Microbiol. 150:735743.

31. Sambrook, J., Fritsch, E. F., and Maniatis, T. 1989. Molecular Cloning: A
Laboratory Manual. Cold Spring Harbor Laboratory, Cold Spring Harbor, NY.

32. Shimamoto, T., Kobayashi, M., Tsuchiya, T., Shinoda, S., Kawakami, H., Inouye, S., and Inouye, M. 2000. A retroelement in Vibrio cholerae. Mol. Microbiol. 34:631-632.

33. Sukno, S. A., Taylor, A. M., and Farman, M. L. 2002. Genetic uniformity among isolates of Peronospora tabacina, the tobacco blue mold pathogen. Phytopathology 92:1236-1244.

34. Tham, F. Y., Lucas, J. A., and Wilson, Z. A. 1994. DNA fingerprinting of Peronospora parasitica, a biotrophic fungal pathogen of crucifers. Theor. Appl. Genet. 88:490-496.

35. Thornbury, D. W., and Farman, M. L. 2000. Re-use of nylon membranes for radioactive hybridizations. Biotechniques 29:1250-1254.

36. Tooley, P. W., and Garfinkel, D. J. 1996. Presence of Ty1-copia group retrotransposon sequences in the potato late blight pathogen Phytophthora infestans. Mol. Plant-Microbe Interact. 9:305-309.

37. van der Biezen, E. A., Juwana, H., Parker, J. E., and Jones, J. D. G. 2000. cDNA-AFLP display for the isolation of Peronospora parasitica genes expressed during infection of Arabidopsis thaliana. Mol. Plant-Microbe Interact. 13:895-898.

38. Voglmayr, H., and Greilhuber, J. 1998. Genome size determination in Peronosporales (Oomycota) by feulgen image analysis. Fungal Genet. Biol. 25:181-195.

39. Wiglesworth, M. D. 1994. Differentation and detection of Peronospora tabacina Adam. using the polymerase chain reaction. Ph.D. thesis. University of Kentucky, Lexington. 